ఠ

\title{
Plasma concentrations and dosing of 2 long-acting injectable formulations of aripiprazole
}

This article was published in the following Dove Press journal:

Neuropsychiatric Disease and Treatment

20 April 2017

Number of times this article has been viewed

\section{Phyllis M Salzman' \\ Arash Raoufinia ${ }^{2}$ \\ Susan Legacy ${ }^{3}$ \\ Pedro Such ${ }^{4}$ \\ Anna Eramo 5}

'Global Medical Affairs, Otsuka Pharmaceutical Development \&

Commercialization, Inc., Princeton, NJ, ${ }^{2}$ Clinical Pharmacology, Otsuka

Pharmaceutical Development \& Commercialization, Inc., Rockville, MD, ${ }^{3}$ US Medical Affairs, Neuroscience, Otsuka Pharmaceutical Development \& Commercialization, Inc., Princeton, NJ, USA; ${ }^{4}$ Medical Affairs Psychiatry, $\mathrm{H}$. Lundbeck A/S, Valby, Denmark; ${ }^{5} \mathrm{Global}$ Clinical Development, CNS, Lundbeck LLC, Deerfield, IL, USA
Correspondence: Arash Raoufinia Clinical Pharmacology, Otsuka Pharmaceutical Development \& Commercialization, Inc. 2440 Research Blvd, Rockville, MD 20850, USA

$\mathrm{Tel}+$ I 2406833170

Email Arash.Raoufinia@otsuka-us.com

\begin{abstract}
Maintaining therapeutic plasma concentrations of an antipsychotic agent is essential in preventing relapse of symptoms in schizophrenia. Long-acting injectable (LAI) formulations provide extended exposure to antipsychotic therapy and have been useful in addressing treatment nonadherence. Aripiprazole is an atypical antipsychotic used in the treatment of schizophrenia and is available in 2 chemically different (aripiprazole monohydrate and aripiprazole lauroxil $[\mathrm{AL}]$ ) and pharmaceutically different LAI formulations (aripiprazole once-monthly $400 \mathrm{mg}$ [AOM 400] and AL). The pharmaceutical difference is that AL, unlike AOM 400, is a prodrug that requires additional metabolic steps to form the active drug aripiprazole. We present data demonstrating that aripiprazole plasma concentrations are similar for AOM 400 and the $882 \mathrm{mg}$ dose of AL when administered once every 4 weeks and that both provide similar therapeutic plasma concentrations of aripiprazole when compared with therapeutic oral doses.
\end{abstract}

Keywords: long-acting injectable, aripiprazole, plasma concentrations, dosing, schizophrenia

\section{Introduction}

Schizophrenia is a chronic disease for which continuous antipsychotic treatment substantially reduces the risk of relapse. ${ }^{1}$ Thus, maintaining plasma drug concentrations within an agent's therapeutic window is critical for achieving optimal outcomes. Aripiprazole, a second-generation antipsychotic, is a dihydrocarbostyril (quinolinone) discovered by Otsuka Pharmaceutical Co., Ltd. (Abilify ${ }^{\circledR}$; Otsuka Pharmaceutical Co., Ltd., Tokyo, Japan). ${ }^{2}$ It is indicated for the treatment of schizophrenia at recommended oral starting and target doses of 10-15 mg per day, and it has been shown to be effective over a dose range of 10-30 mg per day. ${ }^{2}$ The median minimum plasma concentration at steady state $\left(\mathrm{C}_{\text {min,ss }}\right)$ with oral aripiprazole $10 \mathrm{mg}$ daily (the lowest effective dose) has been reported to be $94.0 \mathrm{ng} / \mathrm{mL} .{ }^{3,4}$ Two long-acting injectable (LAI) pharmaceutical alternatives have subsequently become available: aripiprazole once-monthly $400 \mathrm{mg}$ (AOM 400; Abilify Maintena ${ }^{\circledR}$; Otsuka Pharmaceutical Co., Ltd.) and aripiprazole lauroxil (AL; Aristada ${ }^{\circledR}$; Alkermes, Inc., Waltham, MA, USA). AL is a prodrug of aripiprazole that differs chemically from AOM, has a higher molecular weight (660.7 g/mol vs $466.4 \mathrm{~g} / \mathrm{mol}$, respectively), ${ }^{5,6}$ and undergoes 2 steps of hydrolysis for bioconversion to the active drug compound. ${ }^{7}$ The first step is an enzymatic hydrolysis of AL to form $N$-hydroxy-methyl aripiprazole, which is subsequently hydrolyzed in the second step to aripiprazole. ${ }^{7}$ Given that AOM 400 and AL are chemically and pharmaceutically distinct, differences in pharmacokinetics (PK) and bioavailability are possible. For example, to achieve therapeutic aripiprazole concentrations during initiation of therapy, the first dose of AL should be accompanied by daily oral 
aripiprazole for 21 days ${ }^{6}$ and the first dose of AOM should be accompanied by daily oral aripiprazole (or the patient's current oral antipsychotic) for 14 days. ${ }^{2}$ Though dose reductions may be indicated in some patients, such as those with a known P450 CYP2D6 polymorphism resulting in poor metabolism of aripiprazole, $400 \mathrm{mg}$ given every 4 weeks is the standard recommended starting and maintenance dose for AOM. ${ }^{5}$ Several dose strengths of AL are available, leading to the question of which AL dose and dose schedule compares most closely with AOM 400. Herein we present simulated and observed steady-state aripiprazole plasma concentrations after administration of AOM 400 and AL (as available in the public domain) to compare the plasma concentrations of the 2 products.

\section{Sources and description of data PK parameters presented}

All plasma concentration PK values are shown at steady state (ss) and are derived from either simulated or observed plasma concentration data, as described in the following text. Simulations provide the average plasma concentration at steady state $\left(\mathrm{C}_{\text {avg,ss }}\right)$, which is an average of plasma levels during a dosing interval. $\mathrm{C}_{\mathrm{avg}, \mathrm{ss}}$ is calculated by dividing the area under the concentration-time curve (ie, all plasma concentrations during a dosing interval) by the dosing interval. The minimum plasma concentration observed over a dosing interval once steady state is reached, $\mathrm{C}_{\min , \mathrm{ss}}$, is typically used as a clinically relevant concentration related to efficacy ${ }^{8}$ and is usually lower than $\mathrm{C}_{\text {avg,ss }}$ for a given agent and dosing regimen. Based on available data, this report presents simulated predictions of aripiprazole $\mathrm{C}_{\text {avg,ss }}$ for $\mathrm{AOM} 400$ and $\mathrm{AL}$, as well as observed aripiprazole $\mathrm{C}_{\text {min,ss }}$ for each.

In this study, the lower boundary of the therapeutic window for aripiprazole is defined as the median $\mathrm{C}_{\text {min,ss }}$ of the lowest, approved, safe, and effective oral dose (10 mg once daily) of aripiprazole in schizophrenia $(94.0 \mathrm{ng} / \mathrm{mL}),{ }^{3,4}$ and each aripiprazole LAI product is compared with this median $\mathrm{C}_{\text {min,ss }}$ value.

\section{Data sources AOM}

Simulated aripiprazole $\mathrm{C}_{\mathrm{avg}, \mathrm{ss}}$ for AOM 400 was derived from a population PK model. Individual empirical Bayes estimates of PK parameters were obtained for the final PK models using data from previously reported studies in patients who received either deltoid $(n=84)$ or gluteal $(n=91)$ injections of AOM 400. ${ }^{9,10}$ These estimates were used to predict individual steady-state PK profiles after 12 once-monthly doses using the numeric integration and basic PK modeling processes of NONMEM ${ }^{\circledR}$ (ICON plc, Dublin, Ireland). ${ }^{11}$ From the simulated datasets, plasma aripiprazole concentrations on post-dose days $0,4,8,12,16,20,24$, and 28 for both deltoid and gluteal AOM 400 administration were utilized to estimate $\mathrm{C}_{\mathrm{avg}}$ values. Simulated $\mathrm{C}_{\mathrm{avg}, \mathrm{ss}}$ for oral aripiprazole $10 \mathrm{mg}, 20 \mathrm{mg}$, and $30 \mathrm{mg}$ were derived from a series of simulations using a dataset of 10,000 cytochrome P450 2D6 extensive metabolizers randomly generated based on observed significant covariate relationships (Otsuka America Pharmaceutical, Inc., unpublished data, 2011). This population was used to predict individual steady-state PK profiles, with corresponding parameter estimates taken from a previously developed population PK model for aripiprazole oral tablets and the numeric integration process of NONMEM. The final PK model simulated 100 once-daily oral aripiprazole doses for each dose level to estimate the $\mathrm{C}_{\text {avg,ss }}$ during the dosing interval.

Observed aripiprazole $\mathrm{C}_{\text {min,ss }}$ following multiple doses of AOM 400 at the deltoid site were available from 86 patients with schizophrenia who participated in a randomized, open-label trial ${ }^{9}$ and from 3 additional studies that evaluated aripiprazole $\mathrm{C}_{\text {min,ss }}$ following multiple doses of $\mathrm{AOM}$ 400 at the gluteal site. ${ }^{10,12,13}$ Two of these studies were randomized controlled phase III trials that contributed data from 165 and 214 patients, respectively; ${ }^{12,13}$ the third study was a randomized, open-label PK study that provided data from 10 patients. ${ }^{10}$

\section{$A L$}

Simulated aripiprazole $\mathrm{C}_{\mathrm{avg}, \mathrm{ss}}$ following $\mathrm{AL}$ approved doses (441 mg, $662 \mathrm{mg}$, and $882 \mathrm{mg}$ once monthly; $882 \mathrm{mg}$ every 6 weeks) and oral aripiprazole doses of $10 \mathrm{mg}, 20 \mathrm{mg}$, and $30 \mathrm{mg}$ are available from the Center for Drug Evaluation and Research (CDER) of the US Food and Drug Administration (FDA). ${ }^{14}$ The simulations are based on population PK modeling, using data from 4 phase I clinical trials (ALK9072001, ALK9072-101, ALK9072-002 [NCT01493726], and ALK9072-102) and a single, 12-week, phase III trial (ALK9072-003 [NCT01469039]) conducted by Alkermes and involving a total of 616 subjects. The resulting estimates were used to predict PK profiles after 8 once-monthly doses or 6 every 6 weeks doses.

Median values for the observed $\mathrm{C}_{\text {min,ss }}$ of aripiprazole are publically available only for AL $441 \mathrm{mg}$ and $882 \mathrm{mg}$ given every 4 weeks by intragluteal injection, as evaluated in a 12 -week, randomized, double-blind, placebo-controlled trial. ${ }^{14,15}$ 

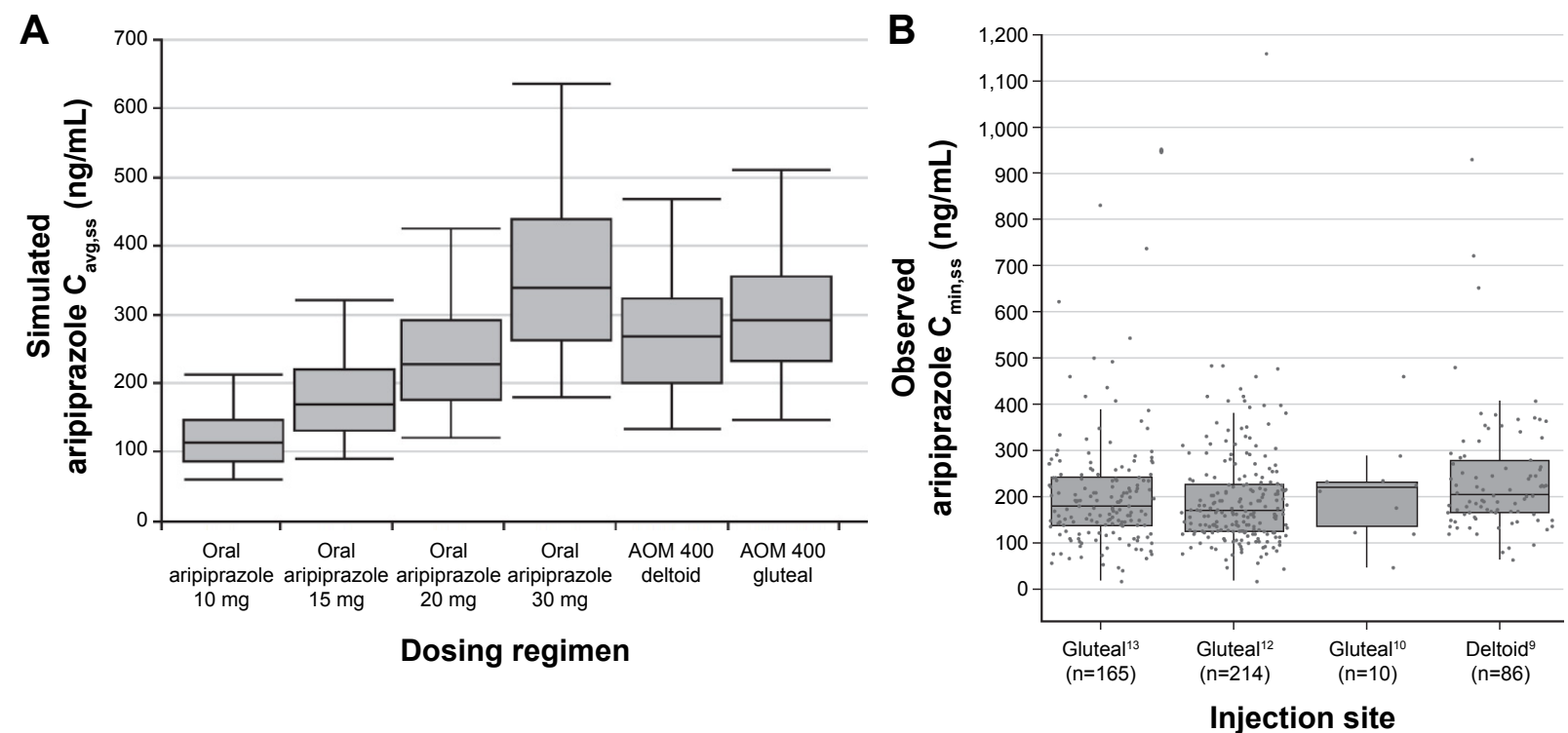

Figure I Simulated aripiprazole $\mathrm{C}_{\text {avg.ss }}$ for oral aripiprazole $10-30 \mathrm{mg} / \mathrm{d}$ and AOM 400 (A), and observed aripiprazole $\mathrm{C}_{\text {min,ss }}$ for AOM 400 (B).

Notes: The thick horizontal bar inside each box is the median value, and the bottom and top edges of the boxes represent the 25 th and 75 th percentiles, respectively. The bottom and top ends of the thin vertical bars represent the 5 th and 95 th percentiles, and points represent observed individual patient values.

Abbreviations: AOM 400, aripiprazole once-monthly $400 \mathrm{mg} ; \mathrm{C}_{\text {avg.ss }}$, average plasma concentration at steady state; $C_{\text {min,ss }}$, minimum plasma concentration at steady state.

\section{Results}

Simulated $\mathrm{C}_{\text {avg,ss }}$ for AOM 400 when given at the deltoid and gluteal sites were $269 \mathrm{ng} / \mathrm{mL}$ and $291 \mathrm{ng} / \mathrm{mL}$, respectively (Figure 1A) (Otsuka America Pharmaceutical, Inc., unpublished data, 2014), and for the $441 \mathrm{mg}$ and $882 \mathrm{mg}$ doses of AL, given every 4 weeks, were $117 \mathrm{ng} / \mathrm{mL}$ and $225 \mathrm{ng} / \mathrm{mL}$, respectively (Figure 2A). ${ }^{14}$ Thus, simulated median $\mathrm{C}_{\text {avg,ss }}$ values for AOM 400 and AL $882 \mathrm{mg}$ every 4 weeks were comparable, while simulated values for $\mathrm{AL}$
$441 \mathrm{mg}$ were substantially lower than those for AOM 400 . Likewise, simulated median $\mathrm{C}_{\text {avg,ss }}$ values for the $662 \mathrm{mg}$ every 4 weeks and $882 \mathrm{mg}$ every 6 weeks AL doses were below that of AOM $400(178 \mathrm{ng} / \mathrm{mL}$ and $150 \mathrm{ng} / \mathrm{mL}$, respectively). ${ }^{14}$

Previously reported clinical trials have shown that observed $\mathrm{C}_{\text {min,ss }}$ values with AOM 400 are comparable between deltoid and gluteal injection sites (Figure 1B). ${ }^{9,10,12,13}$ These data also show that the median observed aripiprazole
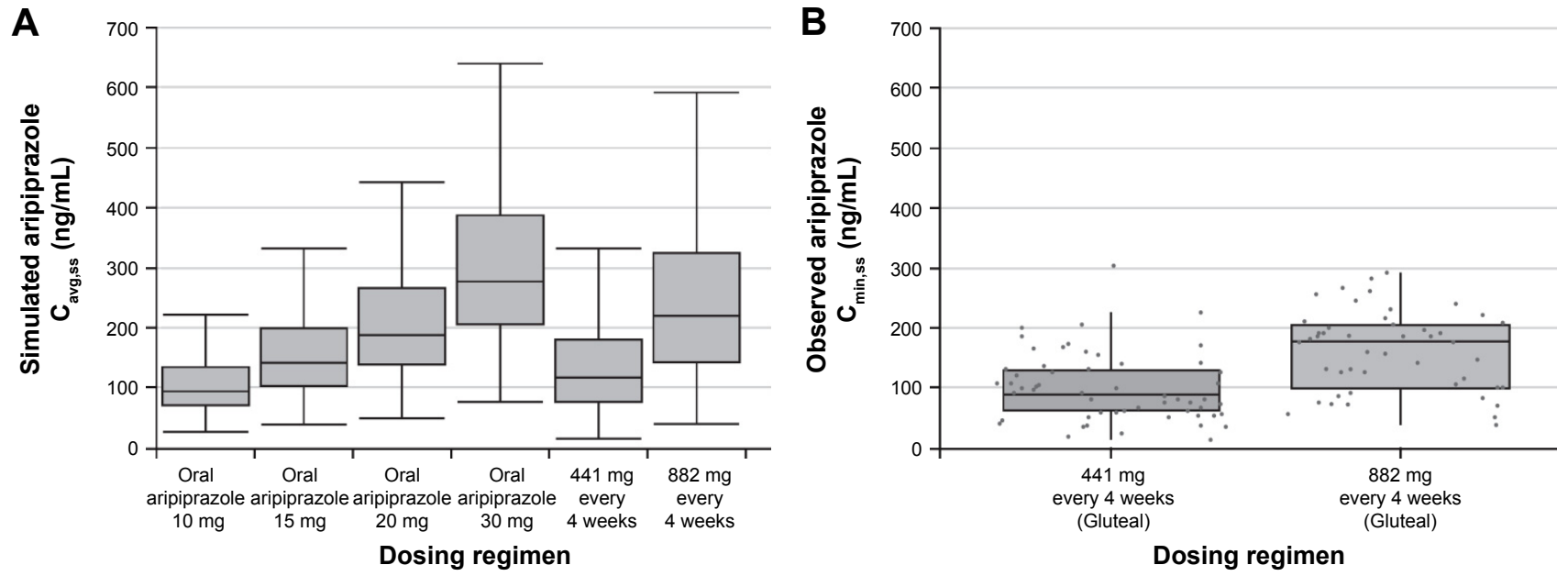

Figure 2 Simulated aripiprazole $C_{\text {avg,ss }}$ for oral aripiprazole $10-30 \mathrm{mg} / \mathrm{d}, \mathrm{AL} 44 \mathrm{I}$ mg every 4 weeks, and AL 882 mg every 4 weeks (A), and observed $C_{\text {min,ss }}$ for AL 44 I mg and $882 \mathrm{mg}$ every 4 weeks (B).

Notes: The thick horizontal bar inside each box is the median value, and the bottom and top edges of the boxes represent the 25 th and 75 th percentiles, respectively. The bottom and top ends of the thin vertical bars represent the 5th and 95th percentiles, and points represent observed individual patient values.

Abbreviations: $\mathrm{AL}$, aripiprazole lauroxil; $\mathrm{C}_{\text {avg,ss }}$, average plasma concentration at steady state; $\mathrm{C}_{\text {min,ss }}$, minimum plasma concentration at steady state. 
$\mathrm{C}_{\text {min,ss }}$ with AOM $400(\sim 200 \mathrm{ng} / \mathrm{mL}$; Figure $1 \mathrm{~B})$ is slightly higher than the median aripiprazole $\mathrm{C}_{\text {min,ss }}$ with AL $882 \mathrm{mg}$ every 4 weeks ( 175 ng/mL; Figure $2 B)$, following intragluteal injection of each. At least half of the observed aripiprazole $\mathrm{C}_{\text {min,ss }}$ for $\mathrm{AL} 441 \mathrm{mg}$ were below the median $\mathrm{C}_{\text {min,ss }}$ for oral aripiprazole $10 \mathrm{mg}$ daily. For AOM 400, 8.4\% of patients overall had aripiprazole $\mathrm{C}_{\text {min,ss }}$ values below $94 \mathrm{ng} / \mathrm{mL}$.

\section{Discussion}

The data reviewed here show that different milligram dosages of the 2 available LAI formulations of aripiprazole, AOM 400 and AL $882 \mathrm{mg}$ given every 4 weeks, provide similar aripiprazole plasma concentrations, despite the fact that AOM 400 provides $400 \mathrm{mg}$ of aripiprazole and AL $882 \mathrm{mg}$ injection contains $600 \mathrm{mg}$ of aripiprazole. ${ }^{6}$ This finding demonstrates that the absolute quantity of drug injected is not an appropriate comparison of the relative efficacy of different formulations. Rather, plasma concentrations are the relevant comparator for efficacy because they reflect not just the dose administered but also the absorption of the drug from the intramuscular space.

AOM 400 has previously been shown to provide median $\mathrm{C}_{\text {min,ss }}$ within the plasma concentration range of oral aripiprazole $10-30 \mathrm{mg}$ daily, ${ }^{3,10}$ and it has been shown to significantly delay relapse versus placebo in the maintenance treatment of schizophrenia for up to 52 weeks. ${ }^{13}$ These data led to FDA approval of AOM 400 for the treatment of schizophrenia. As reviewed here, observed aripiprazole plasma concentrations across 4 clinical trials consistently demonstrated that treatment with $\mathrm{AOM} 400$ provides a median $\mathrm{C}_{\text {min,ss }}$ of $\sim 200 \mathrm{ng} / \mathrm{mL}$.

Plasma concentration data reviewed by the CDER indicate that $882 \mathrm{mg}$ dose of AL given every 4 weeks provides a median $\mathrm{C}_{\text {min,ss }}$ of $\sim 175 \mathrm{ng} / \mathrm{mL}$. The lowest approved dose of AL, $441 \mathrm{mg}$ every 4 weeks, which provided an observed median $\mathrm{C}_{\text {min,ss }}$ below $94.0 \mathrm{ng} / \mathrm{mL}$, was shown to have similar efficacy to that of the $882 \mathrm{mg}$ every 4 weeks dose over 12 weeks in the treatment of acute schizophrenia. ${ }^{15}$ However, no long-term data are available to show comparable efficacy between these $2 \mathrm{AL}$ doses. Because controlled efficacy data beyond 12 weeks are not currently available, the efficacy of AL for delaying symptomatic relapse has not been established.

Available observed plasma concentration data suggest that the aripiprazole median $\mathrm{C}_{\text {min,ss }}$ for AL $882 \mathrm{mg}$ administered every 4 weeks is similar to the aripiprazole median
$\mathrm{C}_{\text {min,ss }}$ for AOM 400, though it should be noted that these data were not obtained from a simultaneous comparison between the 2 LAI formulations. Because the data were derived from different studies, plasma samples were obtained from subjects who may have differed in demographics or clinical characteristics. Upon review of the published reports, no notable differences were observed in subjects in these studies with regard to age (mean age ranged between $\sim 40$ and 47 years), sex (primarily male), or body mass index (mean index $\left.\sim 28 \mathrm{~kg} / \mathrm{m}^{2}\right)$. $^{9,10,12,13,15}$ In most studies, the majority of patients were white, though 1 study enrolled primarily black patients $(76 \%) .{ }^{9}$

It should be recognized that because the data shown for AL in Figure 2 are from a publicly available summary report, ${ }^{14}$ it was not possible to conduct an analysis using patient-level data. It should also be acknowledged that the simulations for $\mathrm{C}_{\text {avg,ss }}$ are based on different time points for AOM and AL. As noted in the prescribing information for each LAI, steady state for each product is reached after 4 once-monthly injections, ${ }^{5,6}$ and the number of doses used in the PK modeling for each product go well beyond this time point. Nevertheless, the $\mathrm{C}_{\text {min,ss }}$ values based on observed data for each product provide the primary basis for our conclusions, and these steady-state values remain constant regardless of the number of doses.

\section{Conclusion}

Observed plasma concentrations can be used to compare different formulations of the same antipsychotic agent. Based on observed data from patients with schizophrenia, steady-state aripiprazole plasma concentrations are similar when LAI formulations are administered every 4 weeks as AOM 400 or as AL $882 \mathrm{mg}$.

\section{Acknowledgments}

Editorial support for development of this manuscript was provided by Sheri Arndt, PharmD, at C4 MedSolutions, LLC (Yardley, PA), a CHC Group company, and funded by Otsuka Pharmaceutical Development \& Commercialization, Inc., and $\mathrm{H}$. Lundbeck A/S.

\section{Disclosure}

PM Salzman, A Raoufinia, and S Legacy are employees of Otsuka Pharmaceutical Development \& Commercialization, Inc.; P Such is an employee of H. Lundbeck A/S; and A Eramo is an employee of Lundbeck LLC. The authors report no other conflicts of interest in this work. 


\section{References}

1. Hasan A, Falkai P, Wobrock T, et al; WFSBP Task Force on Treatment Guidelines for Schizophrenia. World Federation of Societies of Biological Psychiatry (WFSBP) guidelines for biological treatment of schizophrenia, part 2: update 2012 on the long-term treatment of schizophrenia and management of antipsychotic-induced side effects. World J Biol Psychiatry. 2013;14(1):2-44.

2. ABILIFY ${ }^{\circledR}$ (aripiprazole) [prescribing information]. Tokyo: Otsuka Pharmaceutical Co., Ltd.; 2016.

3. Mallikaarjun S, Salazar DE, Bramer SL. Pharmacokinetics, tolerability, and safety of aripiprazole following multiple oral dosing in normal healthy volunteers. J Clin Pharmacol. 2004;44(2):179-187.

4. Center for Drug Evaluation and Research. Application Number: 202971Orig1s000 Clinical Pharmacology and Biopharmaceutics Review(s). Silver Spring: Food and Drug Administration; 2011.

5. Abilify Maintena ${ }^{\circledR}$ US (aripiprazole) [prescribing information]. Tokyo: Otsuka Pharmaceutical Co., Ltd.; 2016.

6. Aristada ${ }^{\circledR}$ (aripiprazole lauroxil) [prescribing information]. Waltham: Alkermes, Inc.; 2016.

7. Rohde M, M Rk N, Håkansson AE, et al. Biological conversion of aripiprazole lauroxil - an $\mathrm{N}$-acyloxymethyl aripiprazole prodrug. Results Pharma Sci. 2014;4:19-25.

8. Hiemke C, Baumann P, Bergemann N, et al. AGNP consensus guidelines for therapeutic drug monitoring in psychiatry: update 2011. Pharmacopsychiatry. 2011;44(6):195-235.

9. Raoufinia A, Peters-Strickland T, Nylander AG, et al. Aripiprazole oncemonthly $400 \mathrm{mg}$ : comparison of pharmacokinetics, tolerability, and safety of deltoid versus gluteal administration. Int J Neuropsychopharmacol. Epub 2017 Feb 15.
10. Mallikaarjun S, Kane JM, Bricmont P, et al. Pharmacokinetics, tolerability and safety of aripiprazole once-monthly in adult schizophrenia: an open-label, parallel-arm, multiple-dose study. Schizophr Res. 2013; 150(1):281-288

11. Mould DR, Upton RN. Basic concepts in population modeling, simulation, and model-based drug development. CPT Pharmacometrics Syst Pharmacol. 2012;1:e6.

12. Fleischhacker WW, Sanchez R, Perry PP, et al. Aripiprazole oncemonthly for treatment of schizophrenia: double-blind, randomised, non-inferiority study. Br J Psychiatry. 2014;205(2):135-144.

13. Kane JM, Sanchez R, Perry PP, et al. Aripiprazole intramuscular depot as maintenance treatment in patients with schizophrenia: a 52-week, multicenter, randomized, double-blind, placebo-controlled study. J Clin Psychiatry. 2012;73(5):617-624.

14. Center for Drug Evaluation and Research. Application Number: 207533Orig1s000 Clinical Pharmacology and Biopharmaceutics Review(s) (Addendum to PBPK, Pharmacometric, Clin Pharm Reviews and Clin Pharm Addendum) and Pharmacometric Review. Silver Spring: Food and Drug Administration; 2015.

15. Meltzer HY, Risinger R, Nasrallah HA, et al. A randomized, doubleblind, placebo-controlled trial of aripiprazole lauroxil in acute exacerbation of schizophrenia. J Clin Psychiatry. 2015;76(8):1085-1090.
Neuropsychiatric Disease and Treatment

\section{Publish your work in this journal}

Neuropsychiatric Disease and Treatment is an international, peerreviewed journal of clinical therapeutics and pharmacology focusing on concise rapid reporting of clinical or pre-clinical studies on a range of neuropsychiatric and neurological disorders. This journal is indexed on PubMed Central, the 'PsycINFO' database and CAS,

\section{Dovepress}

and is the official journal of The International Neuropsychiatric Association (INA). The manuscript management system is completely online and includes a very quick and fair peer-review system, which is all easy to use. Visit http://www.dovepress.com/testimonials.php to read real quotes from published authors. 